\title{
THE ANOKA, MINNESOTA IRON METEORITE AS PARENT TO HOPEWELL METEORITIC METAL BEADS FROM HAVANA, ILLINOIS
}

\author{
Timothy J. McCoy ${ }^{\mathrm{a}}$, Amy E. Marquard ${ }^{\mathrm{a}^{\mathrm{a}}}$, John T. Wasson ${ }^{\mathrm{b}}$, \\ Richard D. Ash ${ }^{\mathrm{c}}$, and Edward P. Vicenzi ${ }^{\mathrm{a}, \mathrm{d}}$
}

${ }^{a}$ Corresponding Author: Department of Mineral Sciences, National Museum of Natural History, $10^{\text {th }}$ and Constitution Aves NW, Smithsonian Institution, Washington, DC 20560-0119 USA (mccoyt@si.edu)

${ }^{\mathrm{b}}$ Dept. of Earth, Planetary and Space Sciences and Dept. of Chemistry and Biochemistry, University of California, Los Angeles, CA 90095-1567 USA.

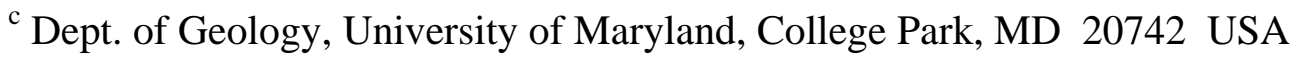

${ }^{\mathrm{d}}$ Museum Conservation Institute, Smithsonian Institution, 4210 Silver Hill Road, Suitland, MD 20746 USA

* Present Address: Department of Chemistry and Biochemistry, University of Colorado at Boulder, 215 UCB, Boulder, CO 80309-0215 USA (Amy.Marquardt@Colorado.edu)

Submitted to Journal of Archaeological Science, July 13, 2016

Revised Jan. 27, 2017 


\begin{abstract}
Although rare among Hopewell horizon artifacts, meteoritic metal represents the most exotic raw material used during the Middle Woodland period in Eastern North America. We demonstrate that Hopewell meteoritic beads recovered from Havana, Illinois can be linked to the Anoka, Minnesota, iron, which fell as a shower of irons across the Mississippi River. The similarity in major, minor and trace element chemistry between Anoka and Havana, the presence of micrometer-sized inclusions of gamma iron in kamacite in both, and the obvious connection via the Mississippi and Illinois Rivers between Anoka and Havana point to the production of the Havana beads from a mass of the Anoka iron. Experiments strongly support the manufacture of the beads via fragmentation of schreibersite inclusions to liberate small pieces of metal. Repeated cycles of heating to temperatures of $600-700^{\circ} \mathrm{C}$ followed by cold-working produced flattened metal sheets. These sheets were subsequently rolled to make the Havana beads. Recovery of the iron mass of Anoka that was used to make the beads likely occurred by local populations who were part of the Trempeleau Hopewell center, with exchange bringing it to the Havana Hopewell center, where the beads were manufactured.
\end{abstract}

Keywords: Hopewell, Meteorite, Trade, Manufacture, Source Material 


\section{INTRODUCTION}

Exotic materials, including copper, silver, obsidian, mica, and shells, and mound building, both earthworks and burial mounds, are hallmark of the Hopewell horizon ( 400 BCE to $400 \mathrm{CE}$; Prufer, 1961) within the Middle Woodland period in Eastern North America. Although a volumetrically miniscule proportion of the artifacts, meteoritic metal represents the most exotic and traceable of these materials. Over the past century, meteoritic iron has figured prominently in the discussion of exotic materials among Hopewell sites. The movement of material between Hopewell sites has alternatively been envisioned as a regularized exchange system with material moving through multiple exchanges before reaching their destination - the Hopewell Interaction Sphere of Struever (1964) - or through long-distance logistic trips to sites of known resources - the "one-shot" model of Griffin et al. (1969).

Although artifacts of irons metal were first recognized from Hopewell sites in modern day Ohio, including from mounds near Chillicothe (Fig. 1), in the early $19^{\text {th }}$ century (Atwater, 1820 ), debate concerning their meteoritic origin began in the late $19^{\text {th }}$ and early $20^{\text {th }}$ century (Kinnicutt, 1884; Kunz, 1890; Farrington, 1902). The famous Tiffany and Company gemologist George Kunz first suggested a connection between numerous Hopewell artifacts from Ohio, including beads and adze blades, and the Brenham, Kansas, pallasite meteorite based on the shape of the included olivine crystals and the relative proportions of metal and olivine in this stony-iron meteorite. A definitive connection between Ohio Hopewell meteoritic iron and the Brenham, Kansas pallasite came with the advent of instrumental neutron activation analyses of meteoritic irons. By determining the trace element chemical composition of both the artifacts and metal within the Brenham meteorite, Wasson and Sedwick (1969) convincingly demonstrated a match. The case for a single meteoritic source was furthered by Struever and 
Houart (1972) in their description of the range of exotic materials present within the Hopewell Interaction Sphere. Alternatively, Prufer (1961) suggested that multiple meteorites were sampled at Hopewell sites in modern-day Ohio, consistent with the significant span of time represented in these sites, and Seeman (1979) argued for multiple sources of meteoritic material within the Hopewell Interaction Sphere based on the widespread geographic distribution of meteoritic metal artifacts. Carr and Sears (1985) provided a more detailed assessment of Middle Woodland meteoritic artifacts, particularly from the Southeastern United States. These authors provided evidence for multiple sources of meteoritic materials, noting that artifacts from Tunacunnhee Mound E and Mandeville Mound B, both from Georgia, required different source meteorites. More broadly, Carr and Sears (1985) noted that numerous iron meteorite falls were likely available to and used by the Hopewell, making it difficult to source any specific meteorite without determination of major, minor and trace elements of the artifact in question. Halsey (1996) provides the most comprehensive recent inventory of meteoritic artifacts from Hopewell sites in his work on the use of metal in the Eastern Woodlands.

A significant impediment to more fully understanding the importance of meteorites in Hopewell culture is the absence of a confirmed relationship between any other Hopewell meteoritic artifact and a known meteorite, other than the Ohio Hopewell-Brenham link. A second confirmed link might provide insights into the mechanisms by which these exotic objects moved from the find site to the ultimate place of archaeological deposition. In this study, we build on preliminary work of Marquardt et al. (2008) and McCoy et al. (2008) to present evidence supporting a link between meteoritic metal beads from the Havana, Illinois, site and a known meteorite find (Anoka) near modern-day Minneapolis, Minnesota, and discuss the implications of such a link. 


\section{HAVANA HOPEWELL METEORITIC BEADS}

In the summer of 1945, the Illinois State Museum excavated a group of mounds scheduled to be leveled for the erection of a power plant (McGregor, 1952). Located in Mason County, Illinois, about 1.5 miles south of the town of Havana (Fig. 1), the mounds were located on the alluvial flood plain of the Illinois River. Mound 9 was the largest of these structures with its base $\sim 25$ feet above the level of the river and rose another $\sim 30$ feet to the peak. During excavation of Mound 9, remains of 14 humans were identified. One of these - burial 10 - was a bundle containing bones which exhibited copper stains but no copper ornaments or implements. Also found within this bundle were over 1,000 shell and pearl beads and a string containing twenty-two meteoritic [note: many of the early publications used the now disfavored term "meteoric"] iron beads with intervening shell beads (McGregor, 1952). Arnold and Libby (1951) reported an age of $2336 \pm 250$ years for wood from Havana mound \#9, consistent with ages for the Ohio Hopewell sites.

Grogan (1948) was the first study of the meteoritic beads from the Havana site. Despite extensive weathering that had both coated and infilled the beads with limonite, he recognized the distinctive, yet deformed Widmanstatten pattern within the beads (Fig. 2). The Widmanstatten pattern is the geometric pattern observed on iron meteorites that have been cut, polished and etched. This pattern is the result of cooling and mineral exsolution of the iron-nickel minerals kamacite and taenite when the iron meteorite formed in the core of an ancient asteroid. The texture is a reflection of the chemistry and cooling history of the meteorite and has been used as a classification tool. Grogan (1948) surmised that the beads were produced by rolling a sheet of meteoritic metal itself produced by a combination of cold working and mild heat treatment. 
Wasson and Schaudy (1971) provided the first chemical analysis of the Havana beads. These authors reported elemental concentrations of 11.4 wt. \% nickel, 20.5 ppm gallium, 21.6 ppm germanium and $0.3 \mathrm{ppm}$ iridium, a region of iron meteorite compositional space that is relatively poorly populated. Based on their chemistry and textures, the Havana meteorite beads along with three North American iron meteorites - Anoka, Minnesota; Edmonton, Kentucky; and Carlton, Texas - and the Mungindi iron from Australia formed the new IIIC iron meteorite group, which were subsequently merged with group IIID to form iron meteorite group IIICD. Wasson and Kallemeyn (2002) reevaluated the classification of the IAB and IIICD irons; most members of the former group IIIC were placed in the IAB-sLM subgroup of what is now called the IAB complex. Kimberlin and Wasson (1976) noted that the compositions of the five irons of the IIICD meteorite group differed distinctly from that of the Ohio Hopewell meteoritic artifacts, supporting the hypothesis of Prufer (1961) for multiple sources of meteoritic materials.

Kimberlin and Wasson (1976) also argued that the composition of the Havana meteoritic beads was not a close match chemically to any of the 300 known North American irons, suggesting that the source was either exhausted by the Hopewell or has not been rediscovered. As we discuss below, the most likely source meteorites for the Havana beads among known meteorites exhibited no evidence of sampling from the single collected masses. It is important to note that Kimberlin and Wasson (1976) based their conclusion on analyses by Wasson and Schaudy (1971), who reported a limited number of elements (Ni, Ir, Ga, Ge). Further, the influence of weathering on iron meteorite compositions was only poorly understood at that time, as was the range of variation expected within replicate analyses of the same meteorite. Buchwald (1976) provided a detailed metallographic description of the Havana beads, noting significant metallographic effects of combined cold working by hammering and intermittent heat 
treatments to temperatures estimated at $\sim 650^{\circ} \mathrm{C}$, about the temperature generated by a woodfueled fire. Buchwald (1976) and Carr and Sears (1985) both commented on the similarity between the Havana beads and the Carlton, Edmonton (Kentucky) and Anoka iron meteorites. Carr and Sears (1985) further argued that the large meteoritic finds Kenton County (IIIAB iron) and Mt. Vernon (pallasite), both in Kentucky, might have served as sources for Hopewell artifacts. However, Kenton County differs dramatically in composition from any known Hopewell artifact and Mt. Vernon is chemically dissimilar to the Havana beads and was reported to have fallen in 1868.

\section{RE-EXAMINING A LINK BETWEEN ANOKA AND HAVANA}

As noted by Wasson and Schaudy (1971), the Havana beads are chemically grouped with three North American iron meteorites - Anoka, Minnesota; Edmonton, Kentucky; and Carlton, Texas. The first two of these were found within the broad Hopewell Interaction Sphere, while Carlton, Texas - 50 miles southwest of Dallas-Ft. Worth - lies outside this range, but within distances traveled to obtain exotic materials used by the Hopewell culture, such as the distance between the Ohio Hopewell center and the Brenham, Kansas, meteorite find site. While the Havana beads exhibited chemical similarities with these three irons, a significant argument against these meteorites representing the raw material for the beads was that each was found buried as a single mass and none showed any evidence of having pieces removed. Anoka, Minnesota, in particular, was found during excavations about four feet beneath the surface. In 1997, however, an additional mass of the Anoka iron was offered for sale. Discovered in Champlin, Minnesota in 1983 while excavating a sewer, the new mass was chemically identical to Anoka. Interestingly, Champlin and Anoka are on opposite sides of the Mississippi River 
(Fig. 1) at its intersection with the Rum River. Thus, at least two, and quite possibly, more iron masses were deposited along a major waterway travel route.

This conclusion is supported by the projected size of the Anoka mas, as determined through measurement of cosmic-ray produced rare-gas isotopes (Chang and Wänke, 1969), which are produced when a meteorite is exposed to high-energy cosmic rays in space. Larger iron meteorites have their interiors shielded from cosmic-rays by the dense outer layers and all meteorites experience decay of these cosmic-ray produced rare-gas isotopes after they fall to Earth and are shielded by the Earth's atmosphere. Despite a considerable uncertainty in their measurement by decay counting, the unusually low ${ }^{10} \mathrm{Be}$ of $1.6 \pm 1.0 \mathrm{dpm} / \mathrm{kg}$ suggests a preatmospheric radius in excess of $40 \mathrm{~cm}$ and associated pre-atmospheric mass in excess of 4000 $\mathrm{kg}$, far in excess of the recovered mass (K. Welten, pers. comm., 2016). Based on the measured ${ }^{36} \mathrm{Cl} /{ }^{10} \mathrm{Be}$ ratio of $\sim 5$, Chang and Wänke (1969) suggested a relatively young terrestrial age of less than $100 \mathrm{ka}$. This limit would permit the fall of Anoka during the most recent glaciation 15$110 \mathrm{ka}$ ago. A more direct explanation for their occurrence is a shower of irons - meteorites that fell separately after breakup of a larger object during atmospheric entry - occurred in this area in the post-glacial period, producing a strewn field of multiple samples. Unfortunately, even newer techniques for terrestrial age dating of iron meteorites do not have the necessary precision to distinguish between a fall during the glaciation or during the present interglacial period.

The Mississippi River cuts through the Anoka strewn field with erosion creating banks some 15-20 feet high. The new evidence for recovery of multiple masses of Anoka, coupled with a re-examination of the metallography and composition of the Havana beads and the Anoka, Carlton and Edmonton (Kentucky) irons and likely trade routes between these sites and Havana, Illinois, suggests an Anoka mass as the parent for the Havana beads. It seems plausible that a 
mass of this iron was recovered and used during the Middle Woodland period to produce the beads found in Havana, Illinois. To test this hypothesis, we compare the structure and chemistry of the Havana beads and the Anoka iron and examine evidence that suggests that Carlton and Edmonton (Kentucky) were not parental to the beads.

\section{METHODS AND MATERIALS}

We examined three of the Havana meteoritic iron beads, two from the collections of the Smithsonian Institution (USNM 1466) and one from UCLA (109). Each of the beads from the Smithsonian collection had cut and polished surfaces that were perpendicular to the central, limonite-filled hole of the bead, with one also having been cut and polished parallel to, but offset from, the central hole. The bead from UCLA was examined as a polished section and had been cut parallel to, but offset from, the central hole, exposing a surface area of $\sim 9 \times 10 \mathrm{~mm}$. We also examined a polished section of Anoka (USNM 6930) from the sample excavated in 1983. Both the Havana beads and Anoka iron were examined for metallography in reflected light using a Nikon Optiphot polarizing microscope. The major element chemical compositions of the Anoka iron and Havana beads were determined using the JEOL 8900R electron probe microanalyzer at the Smithsonian Institution. Four traverses - three of which were each $3 \mathrm{~mm}$ in length and one of which was $\sim 0.5 \mathrm{~mm}$ in length - were conducted on both a Havana bead and the Anoka iron to determine average iron, nickel, phosphorus and cobalt concentrations. Well-characterized pure element metals $(\mathrm{Co})$, alloys $\left(\mathrm{Fe}_{90} \mathrm{Ni}_{10}\right)$ and minerals (schreibersite, troilite) were used as standards. Microprobe totals of $\sim 100 \mathrm{wt}$. \% suggest minimal alteration and hydration of the material analyzed. 
The polished thin section (UCLA 109) used for metallography and major element composition of the Havana bead was analyzed by laser ablation inductively coupled plasma mass spectrometry (LA-ICP-MS), following the same traverses measured in the electron microprobe for major and minor element composition. Trace element abundances were determined by laser ablation inductively coupled plasma mass spectrometry (LA-ICP-MS) using methods described in previous publications (e.g. Brenan et al., 2003). Samples were ablated using a frequency quintupled Nd-YAG New Wave UP213 ultraviolet laser. Ablated material was entrained in a stream of He $\left(c a .0 .71 \mathrm{~min}^{-1}\right)$ then mixed with $\operatorname{Ar}\left(c a .0 .81 \mathrm{~min}^{-1}\right)$ and introduced into the plasma of a ThermoFinnigan Element 2 inductively coupled plasma mass spectrometer (ICP-MS). Samples were analyzed by carving ablation tracks along the line of the electron probe analyses, at a rate ranging from $10-30 \mu \mathrm{msec}^{-1}$. Spot sizes for analyses were determined by element concentration and sample size, with most sample analyses using an $80 \mu \mathrm{m}$ spot. The laser fluence was controlled to between $2-3 \mathrm{Jcm}^{-2}$ for efficient, non-thermal ablation. Samples, reference materials (iron meteorites Coahuila, Hoba and Filomena) and standards (metals NIST1263a, NIST1158) were analyzed in the same fashion. Nickel, determined by electron probe analysis, was used as an internal standard and concentrations were calculated using modified LAMTRACE software. Isotopes were chosen to avoid elemental and molecular interferences and tuning was carried out to maximize the $1+$ ion whilst minimizing oxide production.

In addition, separate samples of a Havana bead and the Anoka iron were studied for bulk chemical composition at UCLA to determine up to 16 elements (15 plus $\mathrm{Fe}$ ) in metal by instrumental neutron-activation analysis (INAA) in replicate analyses; data for Fe are used for internal normalization (Wasson et al., 2006, 2007; Wasson and Choe, 2009). With INAA, Cr, $\mathrm{Fe}, \mathrm{Co}, \mathrm{Ni}, \mathrm{Cu}, \mathrm{Ga}, \mathrm{As}, \mathrm{Ir}$ and $\mathrm{Au}$ can be measured in all iron meteorites. As discussed in 
Wasson and Choe (2009), we achieve very high precision for $\mathrm{Co}, \mathrm{Fe}, \mathrm{Ga}$ and $\mathrm{Au}$ (95\% relative confidence limits on means (of duplicate analyses) of 1.5 to $3 \%$ ) and high precision (4 to $6 \%$ confidence limits) on $\mathrm{Ni}$, As and Ir. The analytical precision for $\mathrm{Cr}$ is high ( 5\%) but sampling errors can be large and there is a minor interference from the ${ }^{54} \mathrm{Fe}(\mathrm{n}, \mathrm{a}){ }^{51} \mathrm{Cr}$ reaction that adds about $5 \mathrm{mg} / \mathrm{g}$ apparent $\mathrm{Cr}$ to our values (which are not corrected). We achieve confidence limits of 7 to $10 \%$ for concentrations higher than the following values (in $\mathrm{mg} / \mathrm{g}$ ): $\mathrm{Ge}, 150 ; \mathrm{Ru}, 5, \mathrm{Sb}$, $0.20, \mathrm{~W}, 0.3, \mathrm{Re}, 0.10$, Os, 1.0 and $\mathrm{Pt}, 2$. A potential problem with some of our earlier data is $\mathrm{W}$ contamination resulting from cutting with tungsten-carbide tools; in cases with large amounts of contamination, the $\mathrm{W}$ values have been eliminated, but minor amounts of contamination are difficult to spot.

To evaluate the thermal and deformation history of the Havana beads, we performed a series of controlled heating experiments on pieces of the Anoka iron that were cut into rectangular shapes $(\sim 0.5 \times 1 \times 1 \mathrm{~cm})$ using an abrasive saw. Pieces were deformed without heating, heated at temperatures of $500-700^{\circ} \mathrm{C}$ for 3 hours without deformation, and heated at $500-700^{\circ} \mathrm{C}$ for 3 hours with deformation. Heating was conducted in a box furnace and deformation by hammering with steel tools on a steel bench vise. Hammering was done perpendicular to the $\sim 1 \times 1 \mathrm{~cm}$ surface until the piece exhibited significant flattening. Samples were prepared as polished sections and examined for metallography in reflected light using a Nikon optiphot polarizing microscope.

We also undertook a bead making experiment using a wood-fueled fire for heating and lithics for deformation, simulating contemporary Hopewell technology. A cut piece of Anoka measuring $\sim 0.7 \times 1 \times 1.3 \mathrm{~cm}$, containing a prominent $1 \mathrm{~mm}$ schreibersite $\left((\mathrm{Fe}, \mathrm{Ni})_{3} \mathrm{P}\right)$ grain and bounded on one side by the weathered surface of the meteorite, was first subjected to 
deformation without heating. Subsequent thinning was achieved by three cycles of heating for $\sim 15$ minutes in a red-orange wood-fueled fire interspersed with periods of deformation with lithics. This produced a final sheet 2-3 mm thick. A final round of heating was followed by curving of the piece into the groove of a glacially-striated lithic using another stone as a hammer.

Once initially curved, the piece was grasped between two green twigs and easily hammered into a cylinder around one twig. A cross section of the produced bead was examined metallographically.

\section{METALLOGRAPHY}

Our observations of the metallography of the Havana beads and the Anoka iron confirm those of Buchwald (1976). Anoka exhibits a fine-scale Widmanstatten structure, formed during cooling from $\sim 600-300^{\circ} \mathrm{C}$ when low-Ni kamacite exsolves from high-Ni taenite. The average kamacite lamellae width in Anoka is $0.34 \pm 0.05 \mathrm{~mm}$. Kamacite (also called $\alpha$ phase) exhibits subgrain boundaries and shock-produced, plate-shaped twin lamella called Neumann bands decorated by micrometer-sized carbides and taenite (also called $\gamma$ phase). Kamacite also exhibits a pronounced depletion of $\mathrm{Ni}$ adjacent to taenite. Zoned taenite exhibits M-shaped Ni profiles indicative of slow cooling, with rims reaching $~ 35 \mathrm{wt} . \% \mathrm{Ni}$ and the center of taenite lamellae exhibiting the fine grained $\alpha+\gamma$ structure termed duplex plessite (Fig. 3). The availability of new slices of Anoka from the 1983 find reveals features not noted by Buchwald (1976). We examined two slices with a total surface area of $\sim 400 \mathrm{~cm}^{2}$. We observed rare $\sim 5$ $\mathrm{mm}$ troilite $(\mathrm{FeS})$ nodules, whereas troilite was absent in the samples studied by Buchwald (1976). Notably, Buchwald (1976) reported schreibersite $\left((\mathrm{Fe}, \mathrm{Ni})_{3} \mathrm{P}\right)$ as skeletal crystals typically $2 \times 0.1 \mathrm{~mm}$ in size. In contrast, the larger slices of the 1983 Anoka mass include skeletal schreibersites that typically reach $2-3 \mathrm{~cm}$ in length. On one slice, a single, elongate, 
skeletal schreibersite of $12 \mathrm{~cm}$ in length bisects the entire slice and is truncated at the edges of the slice.

In the Havana beads, alternating bands of kamacite and taenite are heavily deformed and roughly concentric to the center of the bead (Fig. 3). Kamacite lamellae range up to $0.25 \mathrm{~mm}$ in width, with intervening taenite typically $30-50 \mu \mathrm{m}$ in width, but ranging up to $\sim 200 \mu \mathrm{m}$. The kamacite is a two-phase mixture of recrystallized $\alpha$ phase of $\sim 20 \mu \mathrm{m}$ in grain size with interspersed 0.5-2 $\mu \mathrm{m}$ gamma-particles. This unequilibrated two-phase mixture suggests heating during the manufacture of the beads to temperatures of $600-700^{\circ} \mathrm{C}$ (e.g., the Dalton iron meteorite; Buchwald, 1976) with formation of taenite $(\gamma)$ phase in kamacite along shockproduced Neumann bands. Neumann bands in kamacite decorated by micron-sized taenite and the carbide cohenite $\left((\mathrm{Fe}, \mathrm{Ni})_{3} \mathrm{C}\right)$ are common in Anoka, while Neumann bands in Carlton and Edmonton (Kentucky) are rare and decorated by micron-sized phosphides called rhabdites. The absence of cohenite in the Havana bead likely reflects the thermal instability of the carbide. Taenite has also been substantially altered. The taenite is zoned with respect to Ni with Mshaped zoning profiles, but with original plessite (two-phase) interiors homogenized (Fig. 4). Buchwald (1976) attributed the recrystallized nature of the kamacite and absence of duplex plessite to cold-working and reheating. Rare schreibersite are heavily fractured and brecciated. As noted originally by Grogan (1948), the outer surface and inner hole are filled with limonite. We note that within the relatively unaltered middle zone, kamacite is preferentially weathered relative to taenite, an observation also made by Buchwald (1976), although this is most prominent in the section studied along the axis of the inner hole (Fig. 3). Alteration of kamacite is minor away from this axis and it was these portions that were sampled for bulk chemistry by electron microprobe and LA-ICP-MS. 


\section{BULK CHEMISTRY}

The Havana bead and Anoka iron yield remarkably similar major and minor element compositions. The average for the Havana bead is 86.9 wt. \% iron, 11.4 wt. \% nickel, 0.12 wt. $\%$ phosphorus and 0.64 wt. \% cobalt. The Anoka iron yielded a composition of 86.8 wt. \% iron, 11.3 wt. $\%$ nickel, 0.04 wt. $\%$ phosphorus and 0.64 wt. \% cobalt. In contrast, both Edmonton (Kentucky) (12.9 wt. \% Ni) and Carlton (13.2 wt. \% Ni) (Wasson and Kallemeyn, 2002) are richer in Ni than either the Havana beads or the Anoka iron. This and other chemical differences, as well as the nature of mineral phases included in kamacite (gamma Fe,Ni metal vs. schreibersite),suggest that Edmonton (Kentucky) and Carlton, although in the same group as the Havana beads and Anoka iron, are not parental to the Havana beads. The difference in phosphorus concentration between the Havana beads and the Anoka iron is undoubtedly due to the heterogeneous distribution of the phosphorus-bearing mineral schreibersite.

Compositions for the Havana bead and the Anoka iron determined by INAA are listed in Table 1. In Fig. 5 we plot some INAA concentration data for several key elements. Shown on the diagram are the members of the IAB main group (IAB-MG) and the three low-Au subgroups IAB-sLH, IAB-sLM, and IAB-sLL. These groups are part of the IAB complex which consists of irons that did not experience efficient fractional crystallization. Also plotted as small black dots are iron meteorites that have high contents of $\mathrm{As}, \mathrm{Au}$ and $\mathrm{Sb}$ and thus appear to be part of the IAB complex but that differ in detailed properties from those in the groups and subgroups.

Two of the elements, Ga and Co, show relatively small ranges within groups but moderately large ranges among all irons. They are thus well suited to show genetic relationships among irons. The element $\mathrm{Ni}$ is the second most abundant element in iron meteorites (after $\mathrm{Fe}$ ). $\mathrm{Ni}$ and Au behave as incompatibles; during crystallization they tend to remain in the melt. On X- 
Y diagrams used to examine interrelationships among iron meteorites, one commonly chooses $\mathrm{Au}$ as the independent variable. Earlier, before Au data were widely available, the data were plotted against $\mathrm{Ni}$.

The element Ir is compatible; during crystallization of a melt it always prefers to enter the solid (crystallizing) metal. Compared to other elements, Ir tends to show large ranges within the irons belonging to a group, and is thus well suited to distinguish these irons from each other. Among the five plotted elements it shows the largest range within the sLM subgroup.

Anoka (Ano) and Havana (Hav) are members of the sLM subgroup shown by squares; to highlight them we have added circles around the squares. The two Havana INAA replicates diverged much more than is common for samples that consist of solid metal; we attribute this to the weathering of the beads. As discussed above, appreciable weathering of the metal (and especially the kamacite) can be seen by microscopic examination. The first analysis has a composition closer to that of other sLM irons, and we infer that it is closer to the original composition prior to weathering. Both analyses are enriched in Au which we attribute to contamination of the small samples in the museum or earlier. The data plotted in Fig. 5 are the data for the first analysis of Havana. If we assume that the Au value of Havana is slightly high (by about 5-10\%) and focus on the other 4 elements, the agreement between Anoka and Havana is remarkably close, the more so considering the weathered condition of the Havana beads.

As discussed above, the other North American irons with compositions relatively similar to Havana are the two IAB-sLM irons from Edmonton, KY and Carlton, TX. These are also in the set of sLM data plotted as squares on Fig. 5. Havana is similar to both of these but its Ir content differs by a factor of 2 or more; that in Edmonton is $0.49 \mu \mathrm{g} / \mathrm{g}, 2.3 \times$ higher, that in Carlton is $0.082 \mu \mathrm{g} / \mathrm{g}, 2.6 \times$ lower. In contrast, the Ir content of Havana is $1.2 \times$ higher than that 
in Anoka; such variations are not uncommon when separate masses of meteorites from the IAB complex are analyzed.

In summary, the INAA compositional data of Havana is close enough to that of Anoka to be fully consistent with the view that an iron from the Anoka shower was the source of the Havana

beads. Laser ablation inductively coupled plasma mass spectrometry was used to determine a broader array of elements, although obtaining a representative bulk analysis is more challenging. Compositions for the Havana beads and the Anoka iron from LA-ICP-MS are shown in Table 2 and Fig. 6a. In general, elements determined by both methods are in reasonable agreement, although concentrations of $\mathrm{Cr}$ and $\mathrm{Pt}$ differ by factors of 3-4. As with the INAA data, the Havana beads and the Anoka iron are remarkably similar in chemical composition (Fig. 6b), with most elements within $10 \%$ between Anoka and Havana. Exceptions are elements concentrated in the phosphate schreibersite (P, Ag; possibly W (Corrigan et al. (2009)) and elements that may have been contaminated by other artefacts (e.g., $\mathrm{Cu}$ )..A much smaller difference in $\mathrm{W}$ is observed in the INAA data, suggesting that schreibersite concentrations differ between the Havana beads and the Anoka iron in bulk, although to a much smaller extent than observed in the LA-ICP-MS data.

\section{MANUFACTURE OF THE HAVANA BEADS}

The basic manufacturing of the Havana beads was described by McGregor (1952). The beads were made by cold-working metal into strips and joining the ends to form a hollow, tubular bead, which was subsequently ground to produce the globular shape. While this basic description is consistent with the morphology of the beads, it does not address how a single, malleable mass of iron was separated to form 22 beads or the exact process by which mixed cold-working and heating occurred. Separating smaller pieces of metal from an iron meteorite 
could be accomplished with repeated cold-working and deformation, but may have been achieved in other ways as well. In the case of the Brenham meteorite that is parental to the Ohio Hopewell meteoritic beads, the metal forms an interconnected network between brittle olivine crystals. Weathering or physical degradation of the olivine crystals leaves a meshwork of metal from which small pieces are relatively easily removed. In contrast, the Anoka iron occurs as coherent, large masses of iron. However, Anoka also contains large crystals of schreibersite which, in some cases, cross cut the iron (Fig. 7). The schreibersite is substantially more brittle than the surrounding metal, perhaps providing a point of weakness from which smaller pieces were removed from a larger mass. Buchwald (1976) observed the limited abundance of schreibersite in the Havana beads, consistent with our observations, and suggested that the beads might have been produced from pieces of metal between the larger schreibersites.

Buchwald (1976) argued that the structures present in the Havana beads suggested both cold-working and intermediate annealing through heating, with the absence of typical $\alpha_{2}$ structure limiting the upper temperature of heating to $750-800^{\circ} \mathrm{C}$. Among our controlled heating and deformation experiments, the combination of deformation with heating to $700^{\circ} \mathrm{C}$ for 3 hours most closely duplicated the Havana bead, although the duplex plessite was not homogenized and the grain size within the recrystallized kamacite was much larger in our experiment $(\sim 200 \mu \mathrm{m})$ than in the Havana bead $(\sim 20 \mu \mathrm{m})$. These differences likely reflect the repeated heating and deformation cycles experienced during manufacture of the Havana bead in contrast to the single heating and efficient deformation in our experiment using controlled heating and deformation with steel tools.

In our experiments using wood-fueled fire and lithics, cold-working in the absence of heating produced extensive fragmentation of the schreibersite and modest thinning of the piece at 
the margins, suggesting that removal of distinct pieces by fragmentation of schreibersite is a viable mechanism. The bead produced by repeated cycles of heating and deformation (Fig. 8) shares a number of similarities with the Havana bead, including curvature and deformation of the Widmanstatten pattern, fragmentation of the schreibersite, and, notably, subgrains in kamacite that are of approximately the same scale $(\sim 20 \mu \mathrm{m})$ and are decorated by $1-2 \mu \mathrm{m}$ gamma $(\gamma)$ particles. Duplex plessite has not been homogenized in the produced bead, perhaps suggesting annealing for longer periods of time or at slightly higher temperature for the Havana beads.

\section{ANOKA TO HAVANA}

The movement from source to final location for these meteoritic beads provides an interesting test of the competing models of the Hopewell Interaction Sphere and the "one shot" expedition model. While most of the exotic materials (e.g., obsidian, mica, copper) used by the Hopewell occurred in abundance at their sources, that is not universally true of meteorites. The Brenham meteorite, which is the source of the meteoritic metal beads identified at the Hopewell mounds in Ohio, has produced many tons of material up to the present. As such, the idea that an expedition might visit that site for the specific purpose of returning material to Ohio seems tenable.

In contrast, the 22 metal beads identified from the Havana mound almost certainly originated from a single mass and additional masses were likely not known to the Hopewell. The pathway from the fall location of the Anoka meteorite in Minnesota and the final location in Havana seems straightforward. The Anoka meteorite fell near the Mississippi and the Havana mounds were located along the banks of the Illinois River, a tributary of the Mississippi (Fig. 1). In this case, the idea of exchange seems more likely, although the exchange of raw material may have occurred between neighboring groups rather than through the series of complex, regularized 
exchange envisioned as the Hopewell Interaction Sphere. The Havana Hopewell center likely interacted with both the adjacent Trempeleau Hopewell (Fig. 1), which extended from southwestern Wisconsin up the Mississippi river to the find site of the Anoka meteorite, as well as the more distant Ohio Hopewell which centers in southern Ohio. Given the singular nature of the Anoka mass used to form the Havana beads, the most likely scenario for recovery was by local inhabitants who were part of the Trempeleau Hopewell. Named for mounds near modern Trempeleau, Wisconsin, this expression of the Hopewell constructed mounds now found in St. Paul, Minnesota, $\sim 50 \mathrm{~km}$ down the Mississippi River from Anoka. The St. Paul mounds were investigated by T.H. Lewis in 1879 (Lewis, 1896a,b), who, among other artifacts, reported the presence of two pieces of hammered native copper. The connection of the Trempeleau and Havana Hopewell via the Mississippi further supports recovery of the Anoka mass by the Hopewell and, ultimately, trade to the Havana center.

Where the beads were manufactured is poorly constrained. Metal working was common among the Hopewell, with copper being the most commonly worked metal to manufacture a variety of ceremonial objects including beads. Copper beads are known from Ohio, Havana and Trempeleau sites (Kocik, 2012), likely reflecting the exchange of stylistic concepts as envisioned as part of the Hopewell Interaction Sphere (Struever, 1964). Among these sites, the most diverse examples of copper working, coupled with the only other known example of meteoritic metal beads, might suggest that the beads were manufactured by the Ohio Hopewell. This would be consistent with the general paucity of copper objects in the Havana mound where the meteoritic metal beads were excavated (McGregor, 1952), suggesting copper working expertise in the Havana Hopewell center. However, given that copper beads have been identified in all three Hopewell centers, the direct connection between Anoka and the Havana site via the 
Mississippi and Illinois rivers, and the absence of comparable composition meteoritic beads among either the Trempeleau or Ohio Hopewell sites (Fig. 1), the most likely scenario suggests manufacture by the Havana Hopewell.

\section{SUMMARY}

Spurred by the recovery of additional masses of the Anoka iron and the realization that a shower of irons occurred near the Mississippi River, we have examined whether the Hopewell meteoritic beads recovered from Havana, Illinois can be uniquely linked to the Anoka fall. The similarity in major, minor and trace element chemistry between Anoka and Havana, the presence of micrometer-sized inclusions of gamma iron in kamacite in both, and the obvious connection via the Mississippi and Illinois Rivers between Anoka and Havana point to the likely production of the Havana beads from a mass of the Anoka iron. In contrast, Carlton and Edmonton (Kentucky) differ in major element chemistry, particularly $\mathrm{Ni}$, and in the nature of mineral phases included in kamacite (gamma Fe,Ni metal vs. schreibersite) from the Havana beads. Our experiments strongly support the manufacture of the beads via fragmentation of schreibersite to liberate small pieces of metal followed by repeated cycles of heating to temperatures of 600$700^{\circ} \mathrm{C}$ followed by cold-working to produce a flattened metal sheet which was subsequently rolled to make the Havana beads. Recovery of the individual mass of Anoka used to make the beads was probably by persons associated with the Trempeleau Hopewell center, with exchanges bringing this material to the Havana Hopewell center, where the beads were manufactured. 
Acknowledgments: The authors thank NASA's Cosmochemistry and Emerging Worlds Programs for financial support of this work, the National Science Foundation REU Program for support for AEM during her undergraduate internship at NMNH/SI, Catherine M. Corrigan, Nicole Lunning, Bruce D. Smith and R. Eric Hollinger (NMNH/SI) for consultation during the study and review of the manuscript, and two anonymous reviewers whose comments helped clarify the manuscript. We also thank Prof. William F. McDonough in the Dept. of Geology at the University of Maryland for advice, support, and access to the ICP-MS laboratory.

Conflicts of Interest: The authors declare that they have no conflict of interest. 


\section{REFERENCES}

Arnold J.R. and Libby W.F. (1951) Radiocarbon dates. Science 113:111-120.

Atwater C. (1820) Description of the antiquities discovering in the State of Ohio. Transactions and Collections of the American Antiquarian Society; Archaeologia Americana 1: 168-178.

Brenan J.M., McDonough W.F. and Dalpe C. (2003) Experimental constraints on the partitioning of rhenium and some platinum-group elements between olivine and silicate melt. Earth and Planetary Science Letters 212: 135-150.

Buchwald V.F. (1976) Handbook of Iron Meteorites. University of California Press, Berkeley.

Carr C. and Sears D.W.G. (1985) Toward an analysis of the exchange of meteoritic iron in the Middle Woodland. Southeastern Archaeology 4: 79-92.

Chang C. and Wänke H. (1969) Berryllium-10 in iron meteorites, their cosmic-ray exposure and terrestrial ages. In Meteorite Research (ed. P.M. Millman), Springer-Verlag, New York, NY, pp. 397-406.

Corrigan C.M., Chabot N.L., McCoy T.J., McDonough W.F., Watson H.C., Saslow S.A. and Ash R.D. (2009) The iron-nickel-phosphorus system: Effects on the distribution of trace elements during the evolution of iron meteorites. Geochim. Cosmochim. Acta 73: 2674-2691.

Farrington O.C. (1902) Meteorite Studies - I. Field Columbian Museum Geological Series Pub. No. $64,310-314$.

Griffin J.B., Gordus A.A. and Wright G.A. (1969) Identification of the sources of Hopewellian obsidian in the Middle West. American Antiquity 34: 1-14.

Grogan R.M. (1948) Beads of meteoric iron from an Indian mound near Havana, Illinois. American Antiquity 13:302-305.

Halsey J.R. (1996) Without forge or crucible: Aboriginal Native American use of metal and metallic ores in the Eastern woodlands. The Michigan Archaeologist 41:1-23.

Kimberlin J. and Wasson J.T. (1976) Comparison of iron meteoritic material from Ohio and Illinois Hopewellian burial mounds. American Antiquity 41:489-493.

Kinnicutt L.P. (1884) Report on the meteoric iron from the altar mounds in the Little Miami Valley, Ohio. Reports of the Peabody Museum of American Archaeology and Ethnology, Cambridge 3: 381-384. 
Kocik C. (2012) Regional variation in Hopewell copper use. Univ. of Wisconsin-LaCrosse Journal of Undergraduate Research 15, 1-29.

Kunz G.F. (1890) On five new American meteorites. Amer. J. Sci. 40, 312-323.

Lewis T.H. (1896a) Pre-historic remains at St. Paul, Minnesota. American Antiquarian and Oriental Journal 18: 207-210.

Lewis T.H. (1896b) Mounds and stone cists at St. Paul, Minnesota. American Antiquarian and Oriental Journal 18: 314-320.

Marquardt A., McCoy T., Vicenzi E. and Ash R. (2008) The source of Hopewell extraterrestrial metal and its anthropological implications. Abstracts of the SAA $73^{\text {rd }}$ Annual Meeting, 359.

McCoy T.J., Marquardt A.E., Vicenzi E.P., Ash R.D. and Wasson J.T. (2008) Meteoritic metal beads from the Havana, Illinois, Hopewell Mounds: A source in Minnesota and implications for trade and manufacture. Lunar and Planetary Science Conference 39, \#1984.

McGregor J.C. (1952) The Havana site. In Hopewellian communities in Illinois, edited by T. Deuel, pp. 43-92. Illinois State Museum, Scientific Papers 5.

Prufer O.H. (1961) Prehistoric Hopewell meteorite collecting: Context and Implications. Ohio Journal of Science 61:341-352.

Seeman M.F. (1979) The Hopewell Interaction Sphere: The evidence for inter-regional trade and structural complexity. Indiana Historical Society, Prehistoric Research Series 5(2).

Struever S. (1964) The Hopewell Interaction Sphere in riverine-western Great Lakes cultural history. In Hopewellian Studies, edited by J. Caldwell and R. Hall, pp. 85-106. Illinois State Museum, Scientific Papers 12.

Struever S. and Houart G.L. (1972) An analysis of the Hopewell Interaction Sphere. In Social Exchange and Interaction, edited by E. Wilmsen, pp. 47-80. University of Michigan, Museum of Anthropology, Anthropological Paper 46.

Wasson J.T. and Sedwick S.P. (1969) Possible sources of meteoritic material from Hopewell Indian burial mounds. Nature 222: 22-24.

Wasson J.T. and Schaudy R. (1971) The chemical classification of iron meteorites - V. Groups IIIC and IIID and other irons with germanium concentrations between 1 and $25 \mathrm{ppm}$. Icarus 14: 59-70.

Wasson J.T. and Kallemeyn G.W. (2002) The IAB iron-meteorite complex: A group, five subgroups, numerous grouplets, closely related, mainly formed by crystal segregation in rapidly cooling melts. Geochimica et Cosmochimica Acta 66: 2445-2473. 
Wasson J. T. and Huber H. (2006) Compositional trends among IID irons; their possible formation from the P-rich lower magma in a two-layer core. Geochim. Cosmochim. Acta 70: 6153-6167.

Wasson J. T. and Choe W. H. (2009) The IIG iron meteorites: probable formation in the IIAB core. Geochim. Cosmochim. Acta 73: 4879-4890.

Wasson, J. T., Huber H. and Malvin, D. J. (2007) Formation of IIAB iron meteorites. Geochim. Cosmochim. Acta 71: 760-781 
Table 1. Mean compositions of Anoka and Havana determined by INAA. The Anoka mean is based on four analyses, weighted in the mean for the quality of the analysis. The Havana mean is the composition determined for the first replicate; the second replicate was similar, but showed appreciable differences attributed to weathering.

$\begin{array}{cccc} & & \text { Anoka } & \text { Havana } \\ \mathrm{Cr} & \mu \mathrm{g} / \mathrm{g} & 21 & 21 \\ \mathrm{Co} & \mathrm{mg} / \mathrm{g} & 5.52 & 5.38 \\ \mathrm{Ni} & \mathrm{mg} / \mathrm{g} & 119.1 & 125.9 \\ \mathrm{Cu} & \mu \mathrm{g} / \mathrm{g} & 196 & 275 \\ \mathrm{Ga} & \mu \mathrm{g} / \mathrm{g} & 18.9 & 22.7 \\ \mathrm{As} & \mu \mathrm{g} / \mathrm{g} & 22.1 & 24.9 \\ \mathrm{Sb} & \mathrm{ng} / \mathrm{g} & 447 & 434 \\ \mathrm{~W} & \mu \mathrm{g} / \mathrm{g} & 0.12 & 0.07 \\ \mathrm{Re} & \mathrm{ng} / \mathrm{g} & 23 & <50 \\ \mathrm{Ir} & \mu \mathrm{g} / \mathrm{g} & 0.176 & 0.198 \\ \mathrm{Pt} & \mu \mathrm{g} / \mathrm{g} & 0.9 & 0.8\end{array}$


Table 2. Bulk composition of Anoka and Havana determined by LA-ICP-MS.

$\begin{array}{cccc} & & \text { Anoka } & \text { Havana } \\ \mathrm{P} & \mathrm{mg} / \mathrm{g} & 0.65 & 1.31 \\ \mathrm{Cr} & \mu \mathrm{g} / \mathrm{g} & 8.1 & 8.6 \\ \mathrm{Fe} & \mathrm{mg} / \mathrm{g} & 860.020 & 868.511 \\ \mathrm{Co} & \mu \mathrm{g} / \mathrm{g} & 6369 & 6259 \\ \mathrm{Ni} & \mathrm{mg} / \mathrm{g} & 121.05 & 113.39 \\ \mathrm{Cu} & \mu \mathrm{g} / \mathrm{g} & 203 & 246 \\ \mathrm{Ga} & \mu \mathrm{g} / \mathrm{g} & 18.8 & 19.6 \\ \mathrm{Ge} & \mu \mathrm{g} / \mathrm{g} & 22.3 & 22 \\ \mathrm{Mo} & \mu \mathrm{g} / \mathrm{g} & 4.2 & 3.8 \\ \mathrm{Ru} & \mu \mathrm{g} / \mathrm{g} & 0.49 & 0.56 \\ \mathrm{Rh} & \mu \mathrm{g} / \mathrm{g} & 0.22 & 0.23 \\ \mathrm{Pd} & \mu \mathrm{g} / \mathrm{g} & 4.90 & 5.20 \\ \mathrm{Ag} & \mu \mathrm{g} / \mathrm{g} & 1.5 & 10.9 \\ \mathrm{~W} & \mu \mathrm{g} / \mathrm{g} & 0.11 & 4.20 \\ \mathrm{Os} & \mu \mathrm{g} / \mathrm{g} & 0.23 & 0.25 \\ \mathrm{Ir} & \mu \mathrm{g} / \mathrm{g} & 0.16 & 0.16 \\ \mathrm{Pt} & \mu \mathrm{g} / \mathrm{g} & 0.23 & 0.22 \\ \mathrm{Au} & \mu \mathrm{g} / \mathrm{g} & 1.5 & 1.7\end{array}$




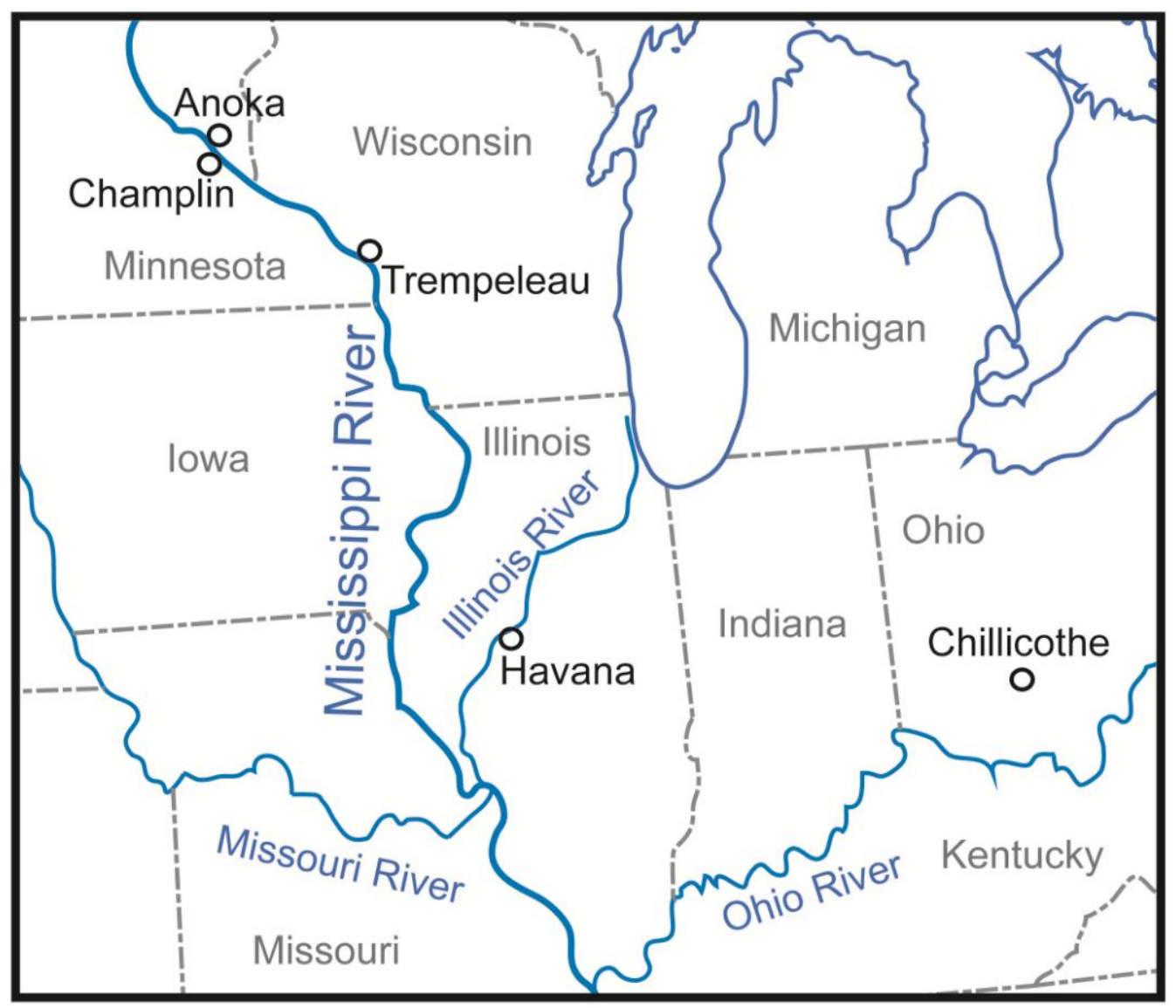

Figure 1. Map of find site of the Anoka iron meteorite in Anoka and Champlin, Minnesota and the recovery site of the Havana meteoritic metal bead in Havana, Illinois. These sites are connected via the Mississippi and Illinois Rivers. Also shown are Hopewell centers near modern-day Chillicothe, Ohio and Trempeleau, Wisconsin. Modern state boundaries shown for reference. 


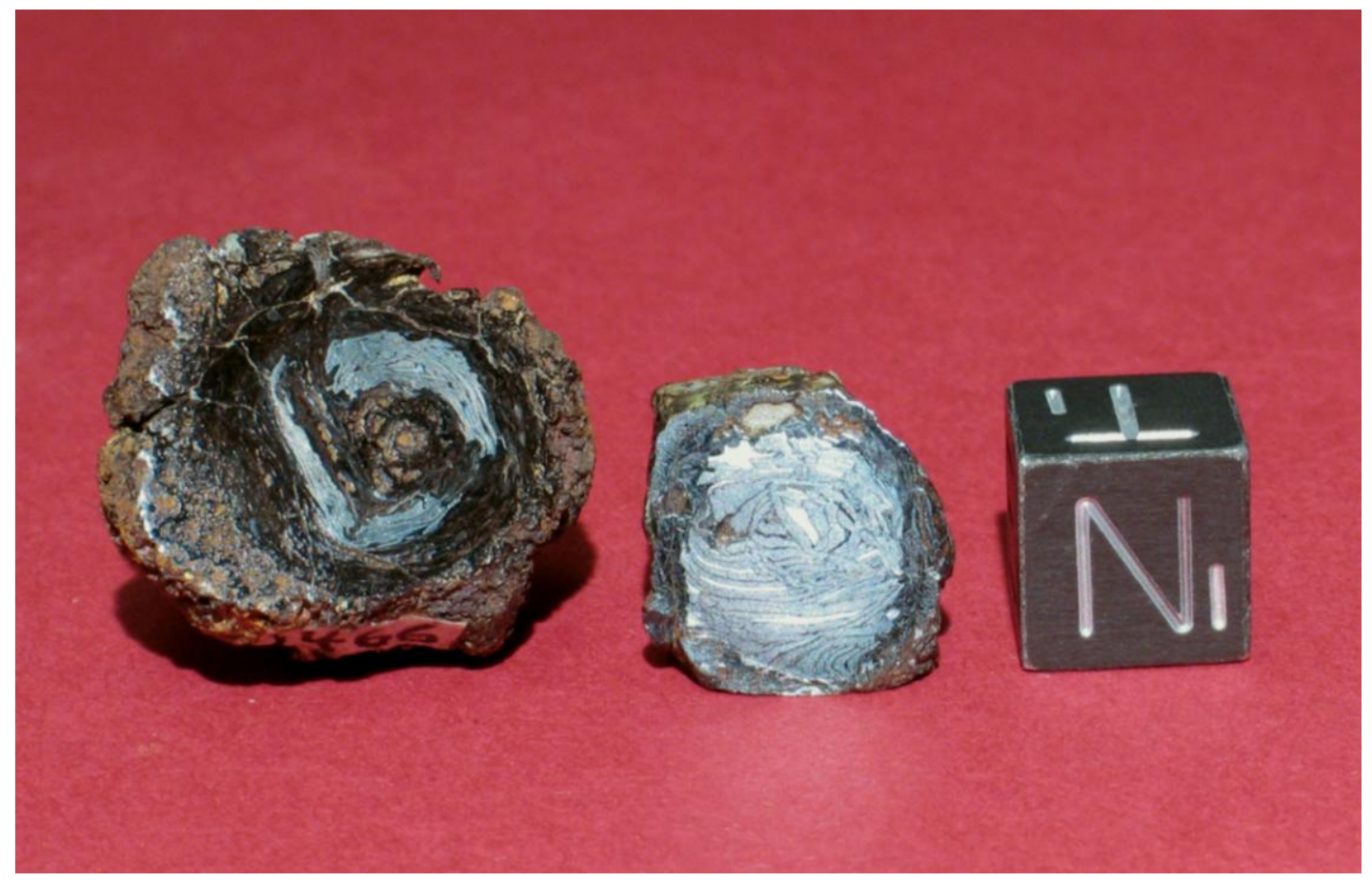

Figure 2. Photograph of two Havana meteoritic metal beads with a $1 \mathrm{~cm}$ cube for scale. The bead on the left (7.8 g mass) is cut perpendicular to the central hole, illustrating the extensive alteration of the bead and infilling of the central hole. The bead on the right (4.6 $\mathrm{g}$ mass) is cut parallel to the central hole and exhibits a concentrically deformed structure. 


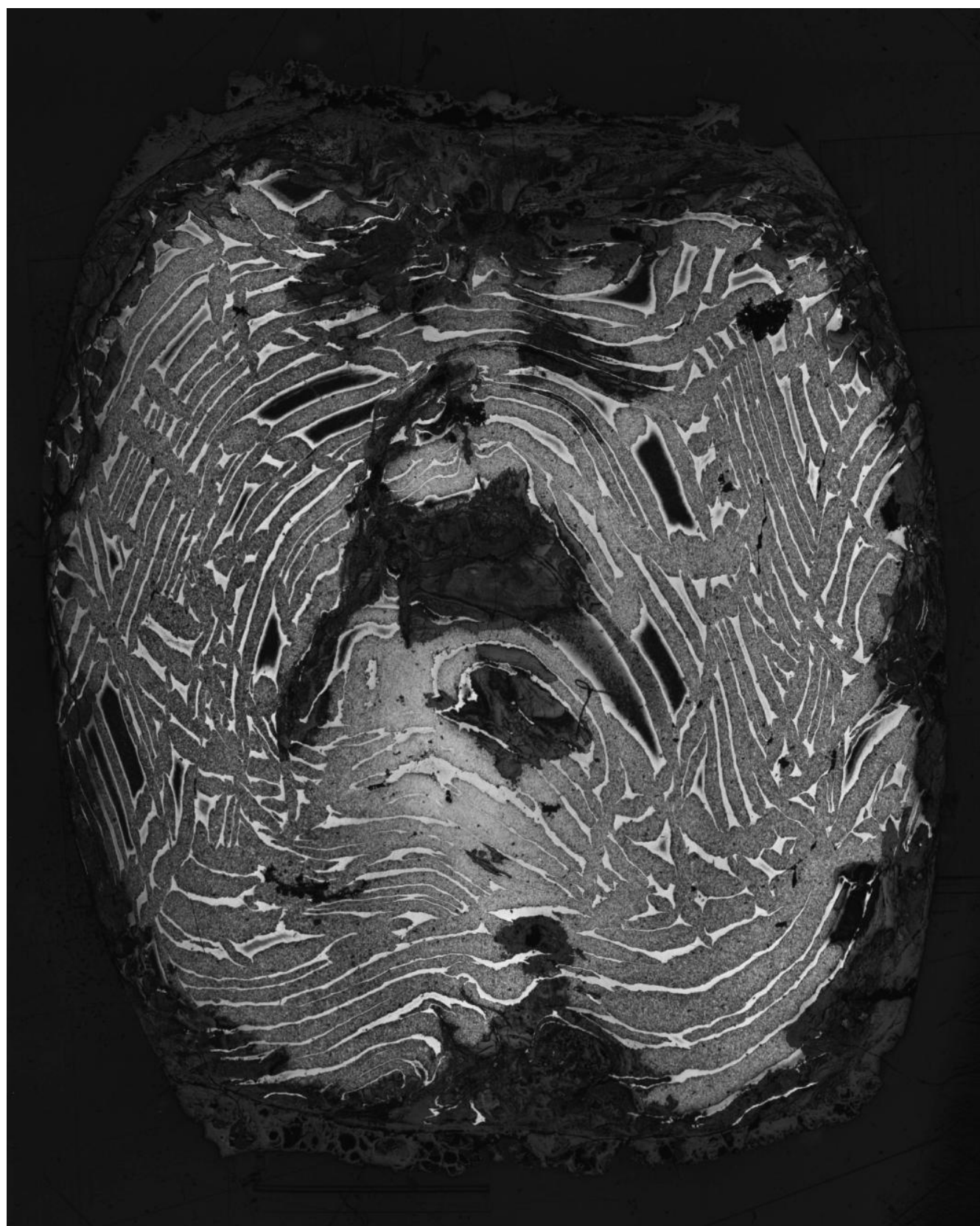

$5 \mathrm{~mm}$

Figure 3. Reflected light photomicrograph of Havana meteoritic metal bead exhibiting deformed lamellae of kamacite (gray) and taenite (white with black interior) which are concentric to the center of the bead. Black patches are areas where hydrated iron oxides (limonite) of terrestrial origin have formed. Note that weathering preferentially alters the low-Ni kamacite phase. 


\section{Taenite Zoning in Anoka and Havana}

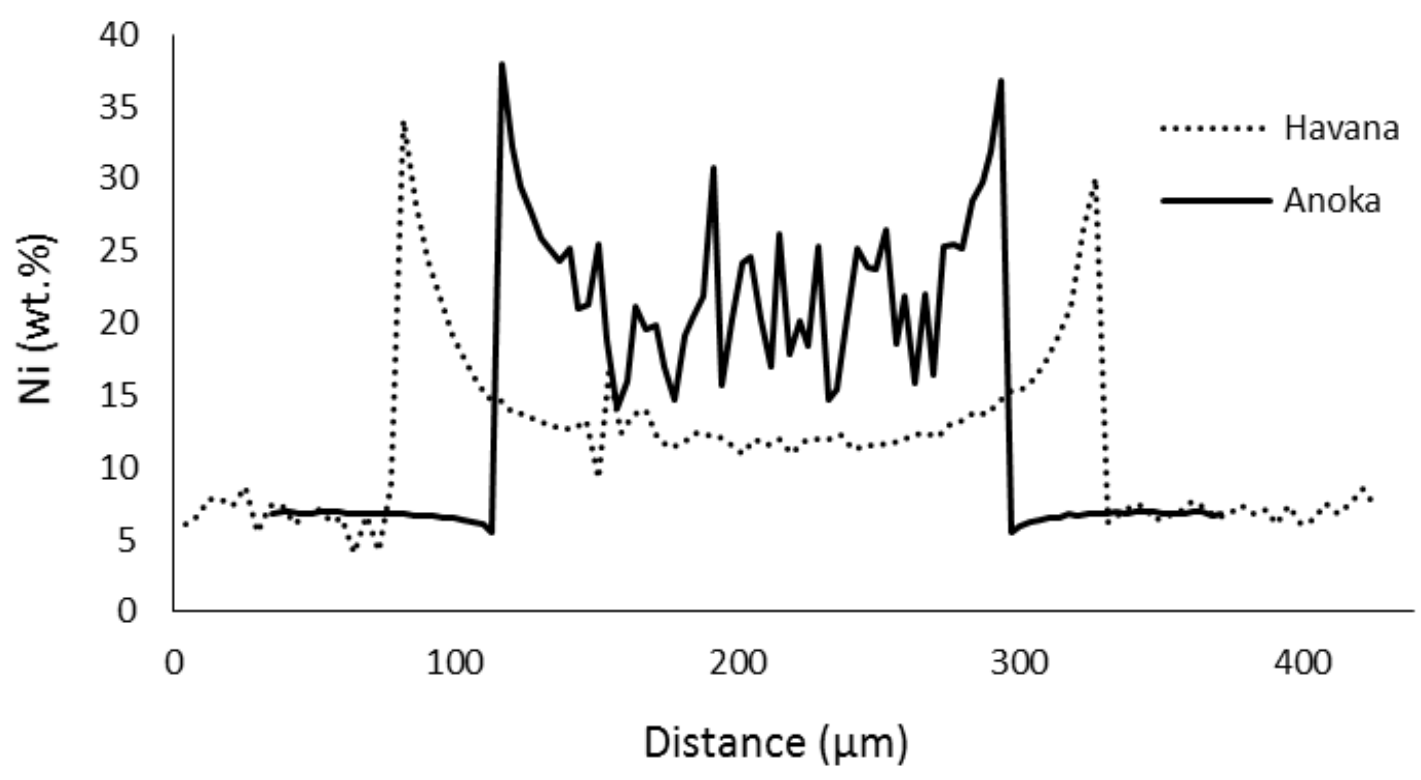

Figure 4. Taenite zoning profiles in Havana and Anoka. Both exhibit M-shaped zoning profiles. The center of Anoka taenite lamellae is duplex plessite, while the center of taenite in Havana has been homogenized by cold-working and reheating (Buchwald, 1976). 

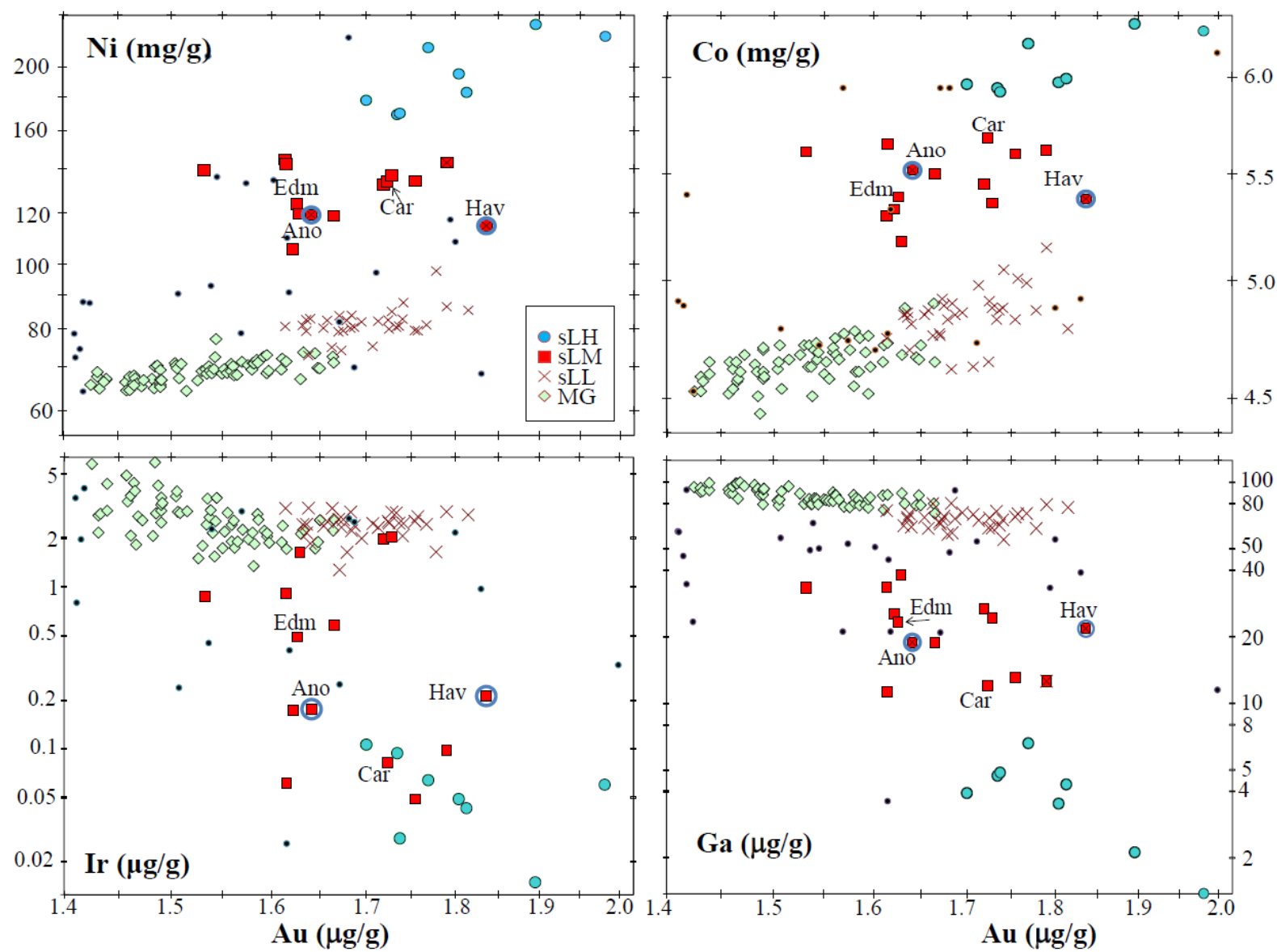

Figure 5. INAA concentration data for several key elements. Shown on the diagram are the members of the IAB main group (IAB-MG) and the three low-Au subgroups IAB-sLH, IABsLM, and IAB-sLL. Small black dots are iron meteorites that have high contents of As, Au and $\mathrm{Sb}$ and thus appear to be part of the IAB complex. Labelled samples are Edmonton, KY (Edm), Anoka, MN (Ano), Havana, IL (Hav) and Carlton, TX (Car). 

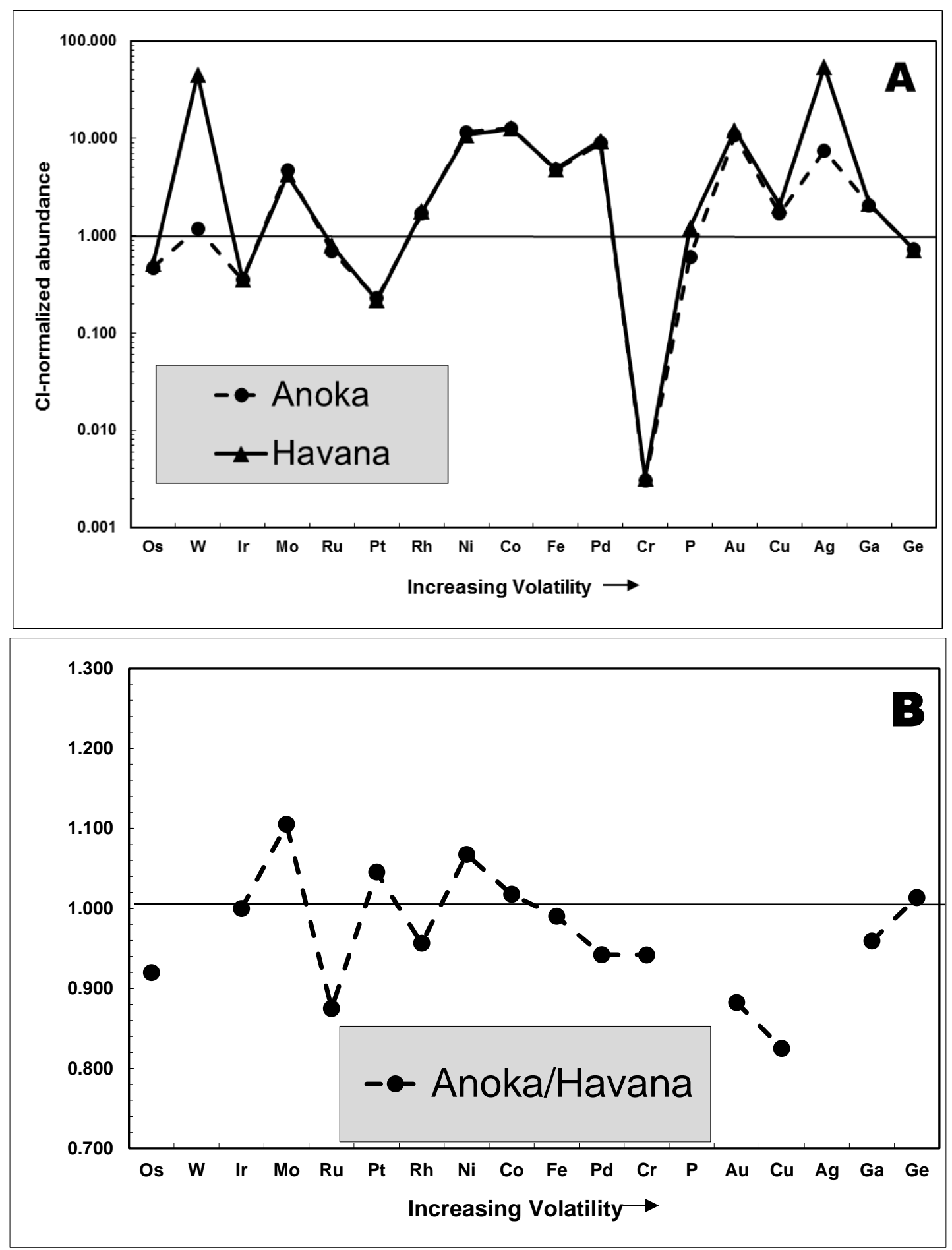

Figure 6. Composition of the Anoka iron meteorite and Havana bead determined by LA-ICPMS, normalized to CI chondrites (A) and ratioed to each other for those elements with ratios between 0.8 and 1.2 (B). The composition of the two are remarkably similar with marked differences in elements concentrated in phosphides ( $\mathrm{P}, \mathrm{Ag}$, possibly $\mathrm{W})$. This data strongly supports that the Anoka iron meteorite was the parent material from the Havana beads were made. 


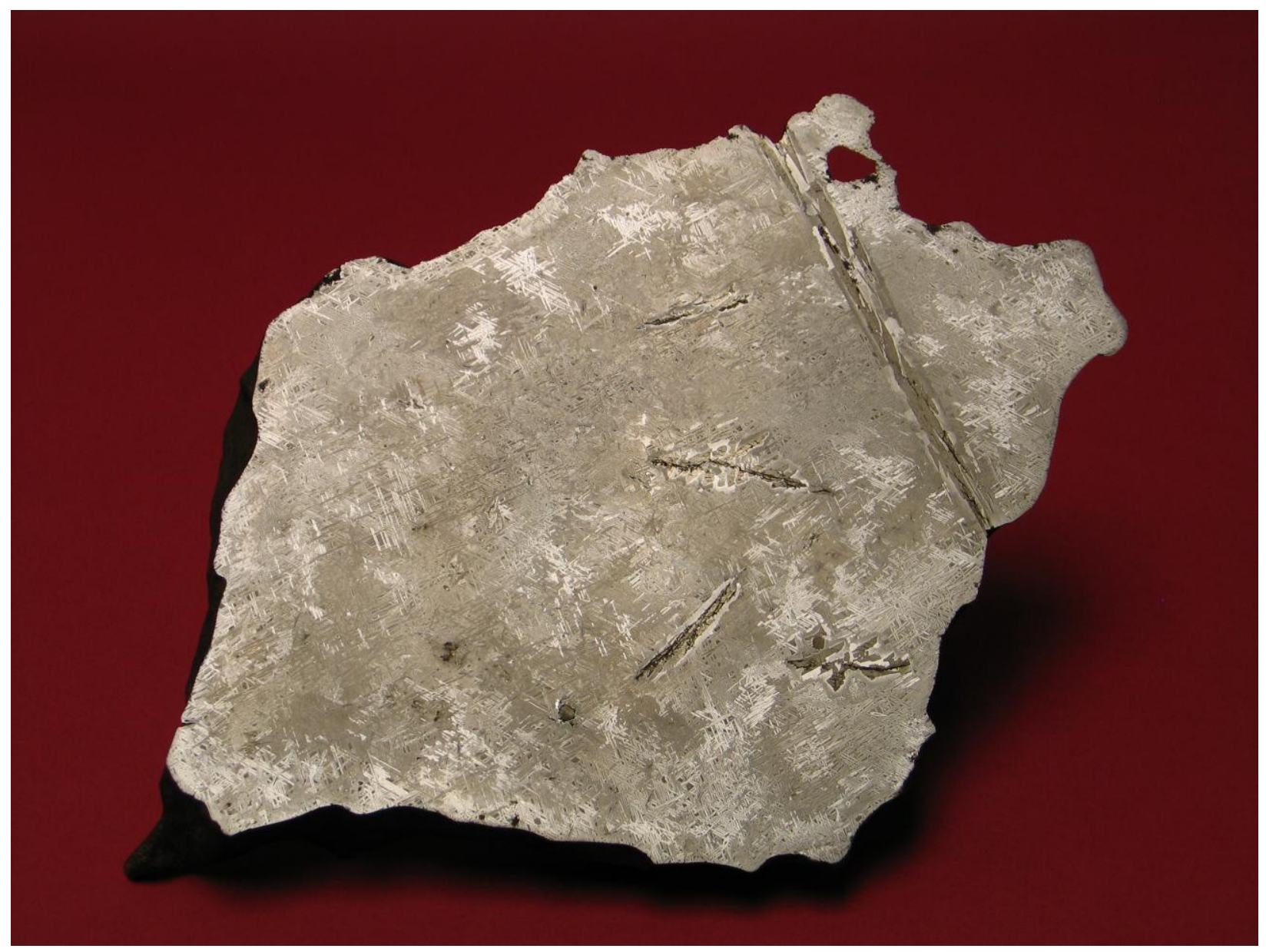

Figure 7. Slice of the Anoka iron exhibiting prominent schreibersite, including a $0.5 \times 12$ $\mathrm{cm}$ skeletal crystal that bisects the slice, and a fine Widmanstatten pattern. Maximum dimension of the slice is $26 \mathrm{~cm}$. 

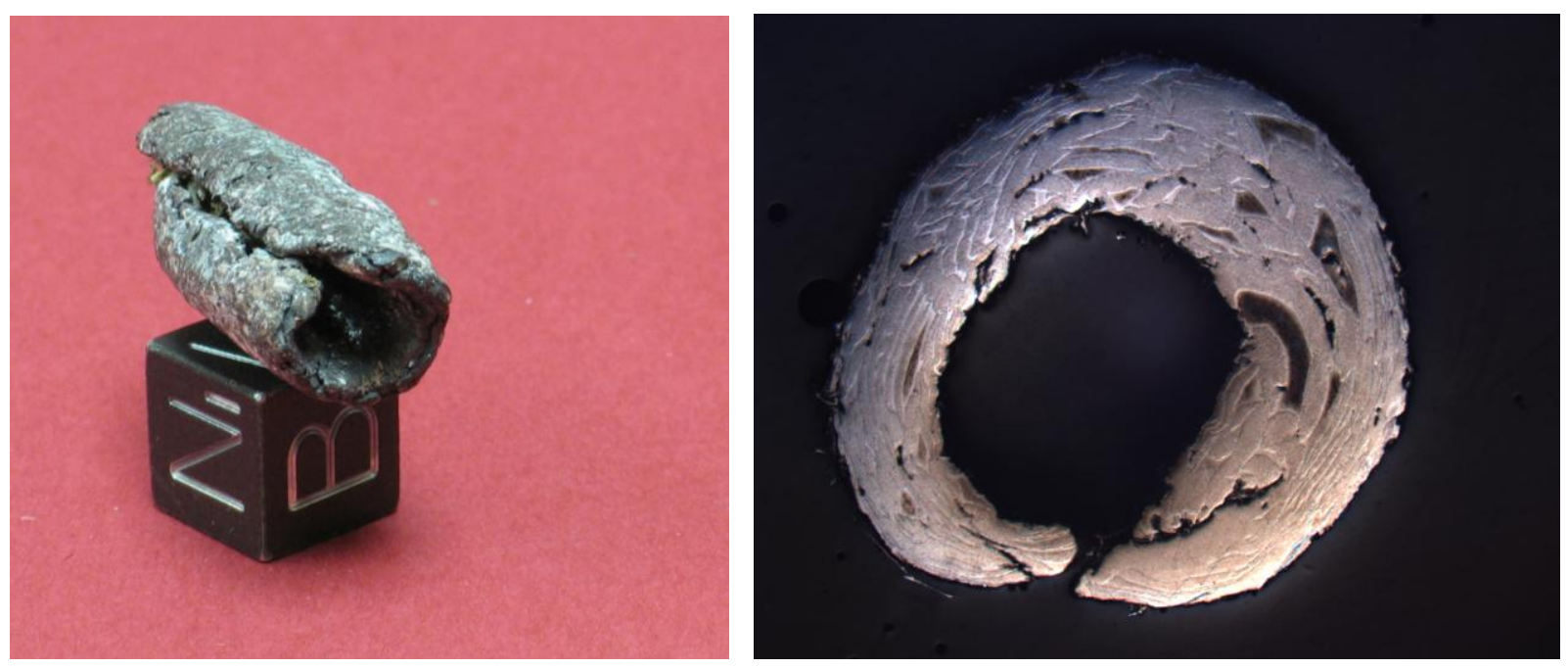

Figure 8. Meteoritic metal bead formed from the Anoka iron using wood-fueled fire for heating and lithics for deformation. Right: Cylindrical bead formed by rolling a flattened sheet. Scale cube is $1 \mathrm{~cm}$ on a side. Left: Reflected light photomicrogaph of a cross section of the bead illustrating the deformation of the Widmanstatten pattern. Bead is $1 \mathrm{~cm}$ in exterior diameter. 